Dextran prophylaxis continued beyond the first two days in immobilised patients may also result in a lower incidence. ${ }^{1011}$ Dextran reduces inhibition of fibrinolysis, ${ }^{12}$ which is maximal three to six days postoperatively ${ }^{13}$; hence further doses might be of value.

Allergic reactions occurred in 22 patients $(1 \cdot 1 \%)$ in the dextran group. This was a higher incidence than that reported by Ring and Messmer ${ }^{14}(0.07 \%)$, but their findings were based on units infused and not on numbers of patients treated. Since preformed dextran-reactive antibodies are reportedly of pathogenic importance in dextran reactions, ${ }^{7}$ application of the hapten-inhibition principle may offer a method of protection. A multicentre trial in seven of the eight hospitals in this study is in progress to evaluate the effect of hapten prophylaxis on allergic reactions. Preliminary findings from over 15000 patients suggest that severe dextran-induced reactions can be prevented.

Although the number of reoperations for haemorrhage was higher in the dextran group, this difference was not significant. When the incidences of all haemorrhagic complications were considered (table Vm) patients in the heparin group fared significantly worse. An explanation may be that prophylaxis with heparin was more readily withdrawn from patients prone to haemorrhage. The two treatment groups lost similar amounts of blood during operation, yet patients in the dextran group were given a larger number of transfusions. Dextran is a plasma expander, however, and decisions to transfuse may have been based on decreased packed cell volume.

The greater number of failures to give a full course of prophylaxis in the heparin group was probably partly accounted for by the number of injections required (21). Dextran infusions form part of normal volume replacement during and after operation and entail no extra work. Possibly heparin could be given more conveniently by, say, jet injection or inhalation.

We conclude that prophylaxis with dextran and low-dose heparin results in the same overall incidence of fatal pulmonary embolism.

We thank the surgeons, pathologists, and nursing staff of the participating hospitals for their co-operation; Barbro Eriksson for designing the computer program; and Annie Lindbom and Eeva Salo for excellent secretarial work. This investigation was supported by grants from the Swedish Medical Research Council (Tom Saldeen) and Fortia AB, Uppsala, Sweden.

Correspondence should be addressed to: Professor Tom Saldeen, Institute of Forensic Medicine, University of Uppsala, Dag Hammarskjölds väg 19, S-752 37 Uppsala, Sweden.

\section{References}

1 Kline A, Hughes LE, Campbell H, Williams A, Zlosnick J, Leach KG. Dextran 70 in prophylaxis of thromboembolic disease after surgery: a clinically oriented randomised double-blind trial. $\mathrm{Br} M e d \mathcal{F} 1975$;ii: 109-12.

${ }^{2}$ Kakkar VV, Corrigan TP, Fossard DP. Prevention of fatal postoperative pulmonary embolism by low doses of heparin: an international multicentre trial. Lancet 1975 ;ii:45-51.

3 Gruber UF. Dextran and the prevention of postoperative thromboembolic complications. Surg Clin North A $1975 ; 55$, No 3:679-96.

4 Bergentz S-E. Dextran in the prophylaxis of pulmonary embolism. World f Surg 1978;2:19-25.

$5 \mathrm{Br}$ Med $\mathcal{F}$ 1975;iii :447-8.

6 Kakkar V. The current status of low-dose heparin in the prophylaxis of thrombophlebitis and pulmonary embolism. World f Surg 1978;2:3-18.

7 Hedin H, Richter W, Ring J. Dextran-induced anaphylactoid reactions in man. Role of dextran-reactive antibodies. Int Arch Allergy Appl Immunol 1976;52:145-59.

${ }^{8}$ Snedecor GW, Cochrane WG. Statistical methods. Iowa: Iowa State University Press AMES, 1967.

${ }^{9} \mathrm{Kiil}$ J, Axelsen F, Kiil J, Andersen D. Prophylaxis against postoperative pulmonary embolism and deep-vein thrombosis by low-dose heparin. Lancet 1978;i:1115-6.

10 Johnson SR, Bygdeman S, Eliasson R. Effect of dextran on postoperative thrombosis. Acta Chir Scand 1968; suppl 387:80-2.

11 Evarts CM, Feil EI. The influence of low-molecular-weight dextran on venous thrombosis following elective hip surgery. $\mathcal{F} A M A$ 1970;212:872.

12 Carlin G, Saldeen T. Effect of dextran on fibrinolysis inhibition activity in serum. Thromb Res 1978;12:1165-75.

13 Bagge L, Saldeen T. The primary fibrinolysis inhibitor and trauma. Thromb Res 1978;13:1131-6.

14 Ring J, Messmer K. Incidence and severity of anaphylactoid reactions to colloid volume substitutes. Lancet 1977;i:466-9.

(Accepted 3 October 1979)

\title{
Trimethoprim resistance in Finland after five years' use of plain trimethoprim
}

\author{
P HUOVINEN, P TOIVANEN
}

\section{Summary and conclusions}

A total of 1388 urinary bacterial pathogens were tested for resistance to plain trimethoprim after five years' use of this drug for prophylaxis against urinary tract infections. Samples were obtained in Turku, Finland, where use of the drug is much greater than in other parts of Finland.

Resistance to trimethoprim ( $\geqslant 8 \mathrm{mg} / \mathrm{l}$; agar-dilution method) occurred in $20 \cdot 3 \%$ of strains isolated from outpatients and $39.8 \%$ of strains isolated from inpatients. Escherichia coli and Micrococcus showed low incidences of resistance $(11 \%$ and $13 \%$ respectively in outpatients and $23 \%$ and $19 \%$ respectively in inpatients); Enterobacter, Streptococcus faecalis, and Staphylococcus

\footnotetext{
Department of Medical Microbiology, Turku University, SF-20520 Turku 52, Finland

P HUOVINEN, CAND MED, research associate

$\mathrm{P}$ TOIVANEN, MD, professor of bacteriology and serology
}

epidermidis occupied an intermediate position; and Proteus mirabilis and Klebsiella were resistant in 41-76\% of cases. Similar incidences of resistance were observed to sulphamethoxazole-trimethoprim, sulphamethoxazole, ampicillin, and nitrofurantoin.

These findings together with the rare occurrence of side effects and convenient dosage confirm the usefulness of plain trimethoprim for urinary tract infections.

\section{Introduction}

Combined treatment with sulphonamide and trimethoprim has been widely used for bacterial infections since 1969.1 Plain trimethoprim, however, has certain advantages over the combined regimen, including more convenient dosage and a low incidence of side effects, particularly with doses used for longterm prophylaxis against urinary tract infections. ${ }^{2}$ Nevertheless, an objection to using trimethoprim alone is the risk of increasing resistant bacteria, which might jeopardise the usefulness of the combined agent. ${ }^{2-4}$

Plain trimethoprim for long-term prophylaxis against urinary 
tract infections has been used in Finland since 1973, 2 -the consumption of the drug per inhabitant being $67 \%$ more in the Turku area than in the country as a whole ( $H$ Sundquist, personal communication). We therefore decided to investigate the incidence of resistance to plain trimethoprim in Turku after five years' use of the drug. For comparison we also determined resistance to sulphamethoxazole-trimethoprim, sulphamethoxazole, ampicillin, and nitrofurantoin.

\section{Materials and methods}

We tested all the urinary tract pathogens isolated in our laboratory over eight weeks during July to September 1978. Escherichia coli, however, was collected for study over only two weeks in the middle of the period. Samples were obtained by dipslide (CLED and MacConkey agar; Uricult) and the isolates identified by routine methods, including the API $20 \mathrm{E}$ procedure. ${ }^{5}$ Identical strains isolated from the same patients were included only once. Agar dilution ${ }^{6}$ was used to determine the minimum inhibitory concentrations (MICs) of trimethropim, sulphamethoxazole-trimethoprim (20:1), sulphamethoxazole, ampicillin, and nitrofurantoin on PDM agar (AB Biodisk, Solna, Sweden). Control strains used were E coli K 12 and Staphylococcus aureus K 209.

\section{Results}

A total of 1388 strains were examined, comprising 954 from outpatients and 434 from inpatients (see table). Figures 1 and 2 give the MICs of trimethoprim for strains isolated from the two groups. Applying the MIC generally used in Scandinavia to determine clinical resistance to trimethoprim $(\geqslant 8 \mathrm{mg} /)^{7}$ we found that strains of bacteria isolated from urinary tract infections fell into three typesnamely, those showing low, intermediate, and high incidences of resistance (genuinely trimethoprim-resistant pseudomonads being excluded)

Distribution of strains isolated from outpatients and inpatients

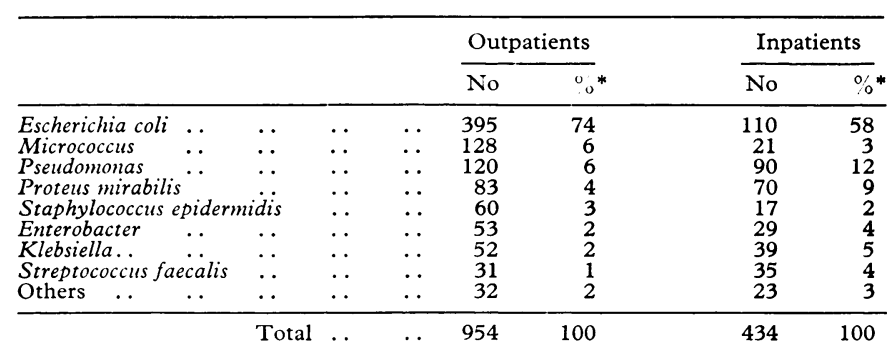

*Weighted percentage: $E$ coli was collected over two weeks and all other strains over eight weeks.
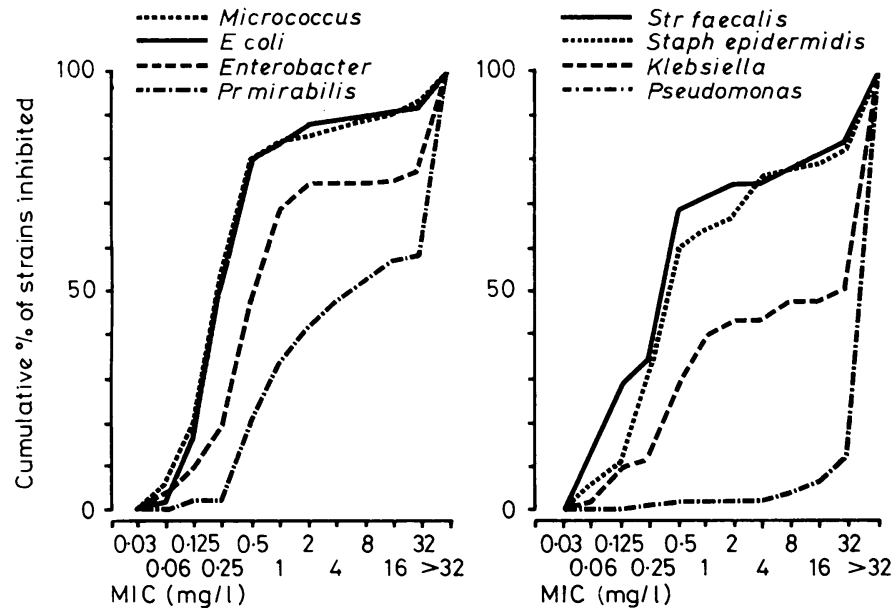

FIG 1-MICs of trimethoprim for strains isolated from outpatients.
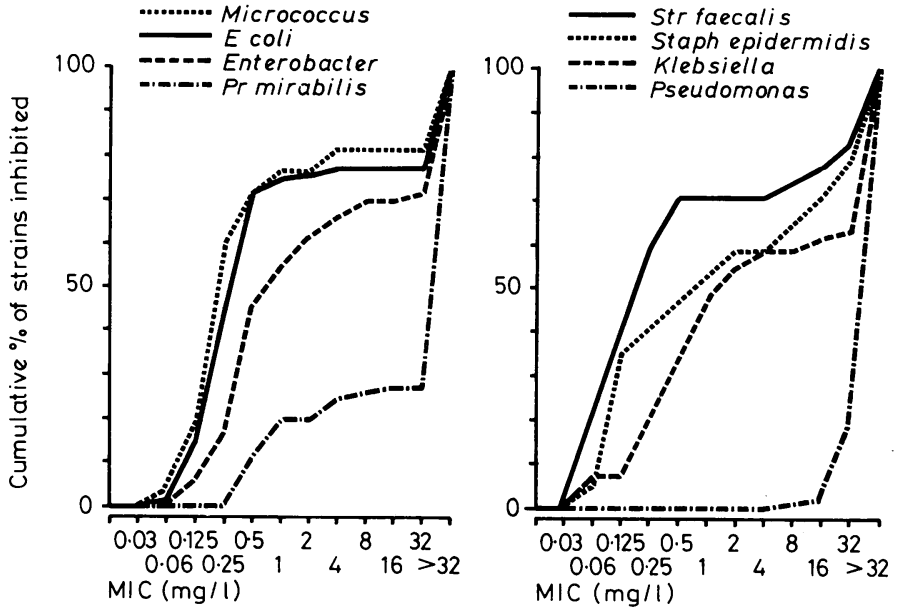

FIG 2-MICs of trimethoprim for strains isolated from inpatients.

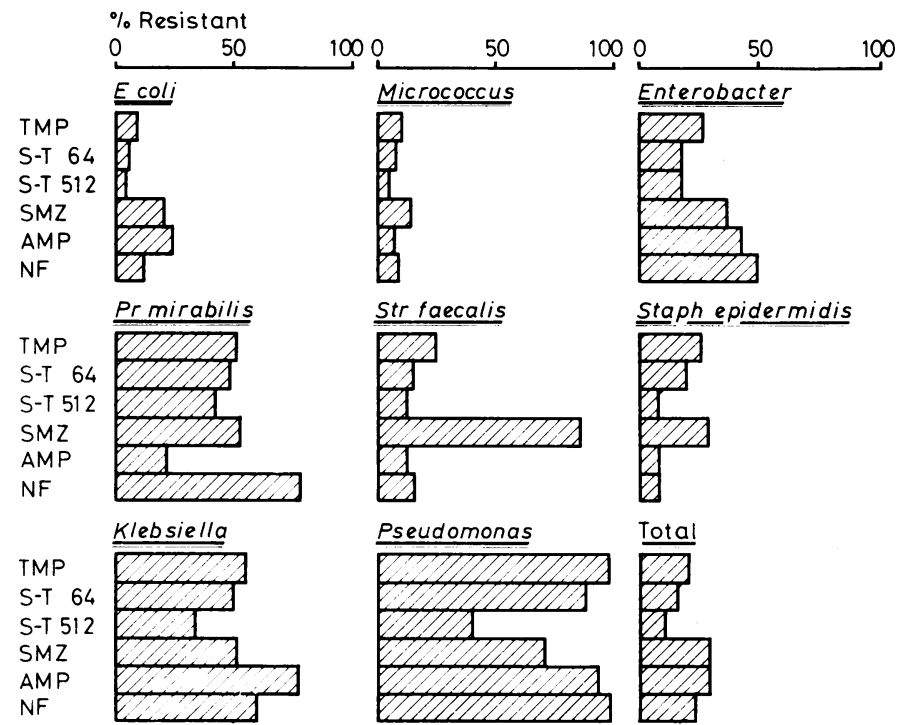

FIG 3-Incidence of outpatient strains resistant to trimethoprim $\geqslant 8 \mathrm{mg} / \mathrm{l}$ (TMP); sulphamethoxazole-trimethoprim $\geqslant 64 \mathrm{mg} / \mathrm{l}$ (S-T 64) and $\geqslant 512$ $\mathrm{mg} / \mathrm{l}$ (S-T 512); sulphamethoxazole $\geqslant 512 \mathrm{mg} / 1$ (SMZ); ampicillin $\geqslant 32 \mathrm{mg} / \mathrm{l}$ (AMP); and nitrofurantoin $\geqslant 64 \mathrm{mg} / \mathrm{l}(\mathrm{NF})$.

E coli and Micrococcus showed low incidences of resistance-namely, $11 \%$ and $13 \%$ respectively in strains isolated from outpatients and $23 \%$ and $19 \%$ in strains isolated from inpatients. Enterobacter, Streptococcus faecalis, and Staph epidermidis occupied an intermediate position, with resistance in $26 \%, 26 \%$, and $25 \%$ of strains respectively from outpatients and $34 \%, 29 \%$, and $41 \%$ of strains respectively from inpatients. Strains showing high incidences of resistance included Proteus mirabilis and Klebsiella; of these, $52 \%$ and $56 \%$ respectively from outpatients and $76 \%$ and $41 \%$ from inpatients were resistant. Pseudomonas from outpatients and inpatients were resistant to trimethoprim in $98 \%$ and $100 \%$ of cases respectively.

Out of 55 "other" strains isolated, all four Serratia species and four of the five Providencia species were resistant to trimethoprim. The remaining 46 strains included 10 different species with under eight isolates for each.

Figures 3 and 4 give the incidences of resistance of the various strains from outpatients and inpatients to trimethoprim and to sulphamethoxazole-trimethoprim $(\geqslant 64 \mathrm{mg} / \mathrm{l})$, sulphamethoxazole $(\geqslant 512 \mathrm{mg} / \mathrm{l})$, ampicillin $(\geqslant 32 \mathrm{mg} / \mathrm{l})$, and nitrofurantoin $(\geqslant 64 \mathrm{mg} / \mathrm{l})$, the figures in parentheses being the MICs used in Scandinavia to test resistance to these drugs. The incidence of resistance to sulphamethoxazole-trimethoprim at an MIC of $\geqslant 512 \mathrm{mg} / 1$ is also shown.

Again the strains fell roughly into groups showing low, intermediate, and high incidences of resistance, there being no clear differences between the five drugs studied. In the 954 outpatient strains examined (pseudomonads included) the incidences of resistance 


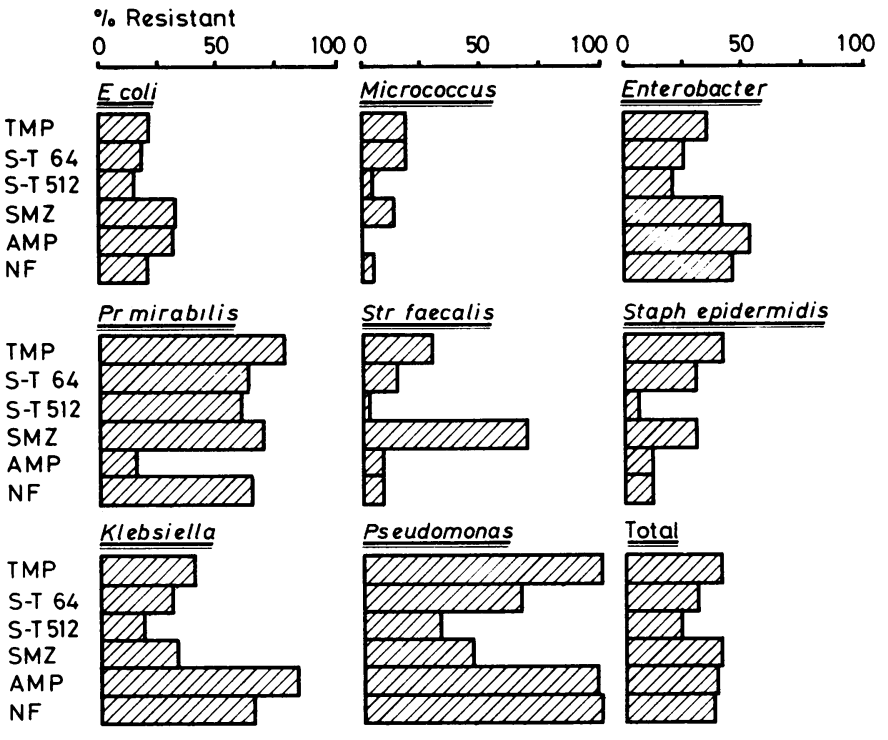

FIG 4-Incidence of inpatient strains resistant to agents listed in fig 3.

were $20.3 \%$ to trimethoprim; $16.0 \%$ and $9.5 \%$ to sulphamethoxazoletrimethoprim at MICs of $\geqslant 64$ and $\geqslant 512 \mathrm{mg} / 1$ respectively; $29.0 \%$ to sulphamethoxazole; $28.6 \%$ to ampicillin; and $23.3 \%$ to nitrofurantoin. The corresponding incidences in inpatient strains were $39.8 \%$ to trimethoprim; $30.1 \%$ and $22.5 \%$ to sulphamethoxazoletrimethoprim at the two MICs respectively; $39.5 \%$ to sulphamethoxazole; $39.3 \%$ to ampicillin; and $37.7 \%$ to nitrofurantoin. These percentages are weighted, taking into account that $E$ coli was collected over two weeks and all other strains over eight weeks.

\section{Discussion}

Only a few other such studies have been conducted. Out of 725 coliform bacilli isolated by Lacey et al $^{8}$ in 1971 from different infections, $2.5 \%$ were resistant to trimethoprim (disc method). Fruensgaard and Korner $^{9}$ reported a 9-12\% incidence of resistance to trimethoprim in urinary tract isolates collected in Copenhagen during 1971-2; among $E$ coli strains the incidence of resistance was 1-3\% (disc method). In 1977 Marks et al ${ }^{10}$ reported resistance to trimethoprim in $13.2 \%$ of coliforms examined. Amyes et al, ${ }^{11}$ who used the disc method, found an $11.6 \%$ incidence of resistance to trimethoprim in urinary tract isolates from London inpatients in 1977; in outpatient strains the incidence was $8.0 \%$. As in our series, Proteus, Klebsiella, and Pseudomonas all showed a higher incidence of resistance than other bacteria. McGill ${ }^{12}$ reported resistance to trimethoprim $2 \mathrm{mg} / \mathrm{l}$ in $32 \%$ of $\mathrm{Kl}$ aerogenes isolated from inpatients during 1977-8. Brumfitt et al ${ }^{13}$ collected 4196 strains from urinary tract infections (in outpatients and inpatients) and observed resistance to trimethoprim $2 \mathrm{mg} / 1$ in $4.3 \%$. E coli was the most susceptible, with $1.4 \%$ resistant; Klebsiella was resistant in $18.3 \%$ of cases, Enterobacter in $12.0 \%$, and $\operatorname{Pr}$ mirabilis in $2.1 \%$. Almost all Serratia strains were resistant to trimethoprim.

Hence trimethoprim-resistant strains clearly also commonly occur in countries where trimethoprim is available only combined with sulphonamides. The incidences in the Turku area, however, were higher than in Great Britain and Denmark. It remains to be seen whether the incidences of resistant strains found in 'Turku represent a plateau or are continuing to increase. The much greater use of plain trimethoprim in Turku than in other parts of Finland may explain the low incidence $(\leqslant 1 \%)$ of trimethoprim resistance in $E$ coli observed in the Helsinki area in 1972-7.2

In our series incidences of resistance closely similar to those against plain trimethoprim were observed not only against sulphamethoxazole-trimethoprim but also against sulphamethoxazole alone, ampicillin, and nitrofurantoin-all of which are widely used for treatment and prophylaxis in urinary tract infections. When this is considered together with the clinical benefits of plain trimethoprim (rare occurrence of side effects and convenient dosage) the usefulness of this drug even after five years' wide use is confirmed.

The mechanism of trimethoprim resistance remains to be established. Nevertheless, despite earlier claims R-plasmidmediated resistance to trimethoprim does occur. ${ }^{11}$ 14-17 $^{\text {This }}$ was confirmed in our study, where the incidence of transferable resistance occurred in about $10 \%$ of all trimethoprim-resistant strains (unpublished data).

\section{References}

1 Garrod LP, James DG, Lewis AAG. The synergy of trimethoprim and sulphonamides. Postgrad Med $71969 ; 45$, suppl.

${ }^{2}$ Kasanen A, Anttila M, Elfving R, et al. Trimethoprim. Pharmacology, antimicrobial activity and clinical use in urinary tract infections. Ann Clin Res $1978 ; 10$, suppl 22.

3 Toivanen A, Kasanen A, Sundquist H, Toivanen P. Effect of trimethoprim on the occurrence of drug-resistant coliform bacteria in the faecal flora. Chemotherapy 1976;22:97-103.

4 Sietzen W, Knothe H. Effect of trimethoprim, trimethoprim-sulfamethoxazole, and sulfamethoxazole on the occurrence of drug-resistant Enterobacteriaceae in the human bowel flora. In: Siegenthaler W, Lüthy R, eds. Current chemotherapy, proceedings of 10th international congress of chemotherapy. Washington DC: American Society for Microbiology, 1978:660-2.

5 Appareils et Procédés d'Identification, Imprimerie Nouvelle, 01300 Belley, France.

${ }^{6}$ Ericsson HM, Sherris JC. 2.1.2. The agar dilution method. Acta Pathol Microbiol Scand [C] 1971; suppl 217:11.

${ }^{7}$ Alestig K, Dornbusch K, Ericson C, et al. Resistensbestämning av bakterier: $\mathrm{Ny}$ indelning i känslighetsgrupper-S, I och R. Läkartidningen $1978 ; 75: 4346-8$.

${ }^{8}$ Lacey RW, Bruten DM, Gillespie WA, Lewis EL. Trimethoprimresistant coliforms. Lancet 1972;1:409-10.

${ }^{9}$ Fruensgaard K, Korner B. Alternations in the sensitivity pattern after use of trimethoprim/sulfamethoxazole for two years in the treatment of urinary tract infections. Chemotherapy $1974 ; 20: 97-101$

10 Marks PJ, Bruten DM, Speller DCE. Trimethoprim-resistant coliforms. Lancet $1977 ; 2: 774$.

11 Amyes SGB, Emmerson AM, Smith JT. R-factor mediated trimethoprim resistance: result of two three-month clinical surveys. 7 Clin Pathol $1978 ; 31: 850-4$.

12 McGill RET. Trimethoprim-resistant Klebsiella aerogenes. Lancet 1978 2:156.

13 Brumfitt W, Hamilton-Miller JMT, Grey D. Trimethoprim-resistant coliforms. Lancet 1977;2:926.

${ }^{14}$ Acar JF, Goldstein FW, Gerbaud GR, Chabbert YA. Plasmides de résistance au triméthoprime: Transférabilité et groups d'incompatibilité. Ann Microbiol (Paris) 1977;128A :41-7.

15 Fleming MP, Datta N, Grünberg RN. Trimethoprim resistance determined by $\mathrm{R}$ factors. Br Med $\mathcal{f} 1972 ; 1: 726-8$.

${ }^{16}$ Jobanputra RS, Datta $N$. Trimethoprim $\mathbf{R}$ factors in enterobacteria from clinical specimens. $f$ Med Microbiol 1974;7:169-77.

17 Richards H, Sojka WJ, Datta N, Wray C. Trimethoprim-resistance plasmids and transposons in Salmonella. Lancet 1978;2:1194-5.

(Accepted 9 October 1979)

ONE HUNDRED YEARS AGO SIR,-Having seen severa letters on the morning bath in the columns of your valuable JoURNAL, permit a humble layman to narrate his experience. Some time ago, I tried the cold bath, but, finding it brought on congestion of the liver, shivers, and vomiting, an eminent physician gave me this prescription. Into a hip-bath pour a pailful of hot water at $117 \mathrm{deg}$.; stand in it and lather all over with yellow soap; then sit down, wash off the soap and well sponge all over with the hot water, and then pour over the body the contents of a large canful of cold water, half on chest and half on back, and rub up with a cotton bath-blanket. I have adopted this plan every morning for the past fifteen years; and if any one will only try it, and also wear a flannel bandage, twelve feet by six inches, round the waist, and totally abstain from alcohol of every description, an Arctic winter would have no terrors for him, and colds, coughs, and chilblains would be for ever unknown.-I am, sir, your obedient servant, C E GREENwoOd. (British Medical fournal, 1880.) 